\title{
Effects of Dibutyryl Cyclic AMP on Hyaluronan and Proteoglycan Synthesis by Retroocular Tissue Fibroblasts in Culture
}

\author{
YUMI IMAI, KYOMI IBARAKI, RITSUKo ODAJIMA*, \\ AND YOSHIMASA SHISHIBA* \\ Bone Research Branch, National Institute of Dental Research, \\ National Institutes of Health, Bethesda, MD 20892, USA, \\ and $*$ Division of Endocrinology, Department of Medicine, \\ Toranomon Hospital, Tokyo 105, Japan
}

\begin{abstract}
Deposition of glycosaminoglycan is one of the histological features of Graves' ophthalmopathy. Although retroocular tissue fibroblasts are considered to be responsible for glycosaminoglycan accumulation, it is not known what is stimulating the fibroblasts. There are studies which are in support of and against the role of anti-TSH receptor antibodies in the pathogenesis of Graves' ophthalmopathy. TSH-receptor antibodies increase cAMP as a second messenger in thyroid cells. We studied the effects of dibutyryl cyclic AMP ( $\left.\mathrm{Bt}_{2} \mathrm{cAMP}\right)$ on glycosaminoglycan synthesis by retroocular tissue fibroblasts in order to know whether cAMP can modulate glycosaminoglycan synthesis. Retroocular tissue fibroblasts mainly synthesize hyaluronan, the large chondroitin sulfate proteoglycan and the small chondroitin sulfate proteoglycan as glycosaminoglycan in cell culture. The amount of hyaluronan synthesis was measured as $\left[{ }^{3} \mathrm{H}\right]$ glucosamine incorporation into macromolecule susceptible to hyaluronidase digestion (from Streptomyces hyaluronlyticus). The amount of proteoglycan synthesis was measured as $\left.{ }^{35} \mathrm{~S}\right]$ sulfate incorporation into macromolecules in medium and cell layer fraction. Proteoglycans in medium were further separated into the large proteoglycan and the small proteoglycan on a Superose 6 column. $\mathrm{Bt}_{2}$ cAMP increased both hyaluronan and proteoglycan synthesis by retroocular tissue fibroblasts, especially stimulating the secretion of the large proteoglycan. Effects of $\mathrm{Bt}_{2}$ cAMP on glycosaminoglycan synthesis were then compared with those in adult skin fibroblasts. Although the magnitude of response between the two was indistinct, the stimulation of the large proteoglycan synthesis by $\mathrm{Bt}_{2}$ cAMP was more prominent in retroocular tissue fibroblasts. The results suggest that the regulation of glycosaminoglycan synthesis by retroocular tissue fibroblasts is different from that by adult skin fibroblasts. Although further studies are required to determine its actual role, cAMP stimulates glycosaminoglycan synthesis by retroocular tissue fibroblasts and underlies the mechanism in Graves' ophthalmopathy.
\end{abstract}

Key words: cAMP, Hyaluronan, Proteoglycan, Glycosaminoglycan, Retroocular fibroblast, Graves' disease

(Endocrine Journal 41: 645-654, 1994)

GRAVES' ophthalmopathy is considered to be an autoimmune disorder and is often associated with

Received: December 27, 1993

Accepted: July 15, 1994

Correspondence to: Dr. Yoshimasa SHISHIBA, Division of Endocrinology, Department of Medicine, Toranomon Hospital, 2-2-2 Toranomon, Minato-ku, Tokyo 105, Japan
Graves' disease. Fibroblasts in retroocular tissue are considered to play an important role in the pathogenesis of the disease and to be responsible for glycosaminoglycan accumulation which is one characteristic finding in affected orbit [1, 2]. Bahn et al. demonstrated the existence of autoantibodies which react with a $23 \mathrm{kDa}$ antigen in fibroblasts in 
the sera of patients with Graves' ophthalmopathy [3].

Retroocular tissue fibroblasts are different from fibroblasts from other anatomical regions in several aspects. For example, they are morphologically different from adult skin fibroblasts and synthesize glycosaminoglycans whose composition is different from those of adult skin fibroblasts $[4,5]$. Furthermore the regulation of the synthesis of proteoglycan in retroocular tissue fibroblasts differs from that of adult skin fibroblasts. It was reported that interferon- $\gamma(\mathrm{INF}-\gamma)$ induced HLA DR expression is specific for retroocular tissue fibroblasts when compared with fibroblasts from other anatomical regions [6].

It is important to answer the question what is responsible for an increase in glycosaminoglycan synthesis by retroocular tissue fibroblasts in Graves' ophthalmopathy. In a case of Graves' disease, hyperthyroidism is due to the function of autoantibodies directed against the TSH receptor on thyroid follicular cells. The antibodies stimulated the cell to overproduce thyroid hormone $[7,8]$. There is controversy concerning the role of anti-TSH receptor antibodies in Graves' ophthalmopathy. IgGs from patients with Graves' ophthalmopathy have been shown to stimulate $\left[{ }^{3} \mathrm{H}\right]$ thymidine uptake [9], expression of heat shock protein 72 (HSP 72) [10] and collagen synthesis [11] by retroocular tissue fibroblasts. But IgGs from patients with Graves' ophthalmopathy failed to stimulate glycosaminoglycan synthesis by retroocular tissue fibroblasts at least in one of our studies (unpublished report), whereas IgGs from patients with circumscribed pretibial myxedema stimulated glycosaminoglycan synthesis by adult skin fibroblasts [12]. To obtain a better understanding of the regulation of glycosaminoglycan synthesis by retroocular tissue fibroblasts in Graves' ophthalmopathy, cAMP was studied for its possible role as a mediator of glycosaminoglycan synthesis.

\section{Materials and Methods}

\section{Materials}

Ultrapure guanidine $\mathrm{HCl}$ and urea were obtained from Schwarz/Man Biotech (Cleveland, $\mathrm{OH}, \mathrm{USA}$ ); Minimal essential medium (MEM) from Mediatech (Washington DC, USA); fetal bovine serum from Upstate Biotechnology, Inc. (Lake Placid, NY, USA); bovine serum albumin (BSA), demethyl sulfoxide dextran sulfate and dibutyryl cyclic AMP $\left(\mathrm{Bt}_{2} \mathrm{cAMP}\right.$ ) from SIGMA (St. Louis, MO, USA); normal rabbit serum from Cappel (Durham, NC, USA); chondroitin sulfate $\mathrm{ABC}$ lyase from Seikagaku-kogyo, Tokyo (Tokyo, Japan); hyaluronidase (from Streptomyces hyaluronlyticus) from Calbiochem (San Diego, CA, USA); G-50 spin column and 100 $\times$ Denhardt's solution from 5 -prime-3-prime (Boulder, CO, USA); 3-morpholino propanesulfonic acid (MOPS), diethylpyrocarbonate (DEPC) and formamide from Fluka (Ronkonkoma, NY, USA); Formaldehyde from Mallinckrodt (Paris, KN., USA); 2,5-dephenyloxazole from Fischer Scientific (Fair lawn, NJ, USA); $\left[{ }^{3} \mathrm{H}\right]$ glucosamine $(35 \mathrm{Ci} /$ mmol) from ICN Biomedicals, Inc (Cleveland, $\mathrm{OH}$, USA) and [ ${ }^{35} \mathrm{~S}$ ]sulfate ( $43 \mathrm{Ci} / \mathrm{mg}$ sulfate) from ICN Radiochemicals (Cleveland, OH, USA); $[\alpha-$ $\left.{ }^{32} \mathrm{P}\right] d$ eoxy-cytidine triphosphate (dCTP) $(3,000 \mathrm{Ci} /$ $\mathrm{mmol}),\left[2-{ }^{3} \mathrm{H}\right] g l y c i n e ~(48.4 \mathrm{Ci} / \mathrm{mmol})$ and $[3,4,5-$ ${ }^{3} \mathrm{H}(\mathrm{N})$ ]leucine $(177.3 \mathrm{Ci} / \mathrm{mmol})$ from Du Pont Company (Boston, MA, USA). Multiprime DNA labeling kit from Amersham (Arlington Height, IL, USA). DEAE cellulose paper was from Shleicher \& Schuell (Keene, NH, USA). Sephadex G-50 and Superose 6 from Pharmacia LKB Biotechnology Inc. (Piscataway, NJ, USA); Partisil 5 PAC from Whatman (Hillsboro, OR, USA). Other chemicals obtained were of the purest grade.

\section{Culture of human retroocular tissue fibroblasts and adult skin fibroblasts}

Retroocular connective tissue (so-called fibroadipose tissue) was obtained at the time of surgical correction of orbital fracture (cases 1 and 2) or decompression surgery for Graves' ophthalmopathy (case 3). Fibroblasts were prepared from the tissue as described previously [5]. Adult skin fibroblasts were purchased from NIGMS human genetic mutant cell repository (cases 4 and 5). Fibroblasts were grown to confluence in a $35 \mathrm{~mm}$ dish with $2 \mathrm{ml}$ of MEM medium enriched with $10 \%$ FBS, penicillin 100 units $/ \mathrm{ml}$ and streptomycin 100 units $/ \mathrm{ml}$. On the initial day of each experiment, the medium was replaced with $1 \mathrm{ml}$ of MEM medium containing $0.1 \%$ BSA plus various concentrations of $\mathrm{Bt}_{2}$ cAMP. Cells were then cultured for $48 \mathrm{~h}$ at $37^{\circ} \mathrm{C}$ under $95 \%$ air- $-5 \% \mathrm{CO}_{2}$ in a humidified incubator. During the last $24 \mathrm{~h}$, 
$\left[{ }^{3} \mathrm{H}\right]$ glucosamine $(50 \mathrm{mCi} / \mathrm{ml})$ and $\left[{ }^{35} \mathrm{~S}\right]$ sulfate $(50$ $\mathrm{mCi} / \mathrm{ml}$ ) were added to the medium. Each medium was separated from the cell layer and solid guanidine $\mathrm{HCl}$ was added to make a final concentration of $4 \mathrm{~mol} / \mathrm{l}$. Each cell layer was washed twice in $2 \mathrm{ml}$ of the culture medium without isotopes, and glycosaminoglycans were extracted with $4 \mathrm{~mol} / \mathrm{l}$ guanidine $\mathrm{HCl}$ containing $50 \mathrm{mmol} / \mathrm{l}$ sodium acetate and $2 \%$ triton $\mathrm{X}-100, \mathrm{pH}$ 6.0.

Unincorporated radioactivity was removed from the extracts on a Sephadex G-50 column prepared in disposable $10 \mathrm{ml}$ plastic serological pipettes (bed volume of $8 \mathrm{ml}$ of a maximum $2 \mathrm{ml}$ sample) and equilibrated with $4 \mathrm{~mol} / \mathrm{l}$ guanidine $\mathrm{HCl}, 50 \mathrm{mmol} /$ $l$ sodium acetate and $0.5 \%$ triton $\mathrm{X}-100, \mathrm{pH} 6.0$. The radioactive fraction excluded from the column was collected and radioactivity was counted.

\section{Analysis of proteoglycans}

The radioactive fraction excluded from the Sephadex G-50 column was applied to a Superose 6 column $(1 \times 30 \mathrm{~cm})$ equilibrated with $4 \mathrm{~mol} / l$ guanidine buffer. An aliquot of the radioactive fraction was also analyzed on a Superose 6 column after chondroitin sulfate $A B C$ lyase digestion (see below).

\section{Specific enzyme digestion}

Specific enzyme digestions of glycosaminoglycans were carried out as follows. The radiolabeled macromolecules excluded by the Sephadex G-50 column were dialyzed with distilled water in order to remove $4 \mathrm{~mol} / l$ guanidine buffer. After dialysis and lyophilization, the samples were dissolved in appropriate buffers for subsequent enzyme reactions.

For proteoglycan analyses, the specimen prepared as above was digested with chondroitin sulfate $A B C$ lyase $(0.1 \mathrm{U} / \mathrm{m} l$ in $0.1 \mathrm{~mol} / l$ Tris acetate buffer, $\mathrm{pH} 7.3$ ) at $37^{\circ} \mathrm{C}$ for $2 \mathrm{~h}$. For hyaluronan analysis, the specimen was digested with hyaluronidase (10 $\mathrm{U}$ hyaluronidase from Streptomyces hyaluronlyticus $/ \mathrm{ml}$ in $0.1 \mathrm{~mol} / l$ sodium chloride acetate buffer, $\mathrm{pH} 5.0$ ) at $37^{\circ} \mathrm{C}$ for $1 \mathrm{~h}$.

\section{Degradation of labeled proteoglycan}

When the rate of proteoglycan degradation was studied, cells were labeled with [ $\left.{ }^{35} \mathrm{~S}\right]$ sulfate for 24 $\mathrm{h}$ in the presence of $10 \%$ FBS in culture medium. The medium was removed and the cells were thoroughly washed in medium without isotopes. The cells were then cultured in the medium without isotopes in the presence or absence of $\mathrm{Bt}_{2} \mathrm{cAMP}$ for $24 \mathrm{~h}$. Radioactivity in the medium and the cell layer was measured as already described.

\section{Hyaluronan analysis}

The amount of $\left[{ }^{3} \mathrm{H}\right]$ hyaluronan was determined as radioactivity susceptible to hyaluronidase digestion. The radiolabeled macromolecules excluded by the Sephadex G-50 column were digested with hyaluronidase (from Streptomyces hyaluronlyticus). Digests were chromatographed on a Sephadex G-50 column ( $8 \mathrm{ml}$ bed volume) and fractions were analyzed to determine the portion of radioactivity degraded by the enzyme and were eluted in the included volumes. The amount of $\left[{ }^{3} \mathrm{H}\right]$ hyaluronan thus measured must be adjusted for the specific activity of the UDP-N acetyl hexosamine pool which is known to change under different culture conditions [13]. The specific activity of each culture was calculated from the ratio of ${ }^{3} \mathrm{H}$ to ${ }^{35} \mathrm{~S}$ in the monosulfated chondroitin 4-S disaccharide derived from the chondroitin sulfate as described previously [14]. Briefly, another aliquot of the sample was digested with chondroitin sulfate $A B C$ lyase $(0.1 \mathrm{U} / \mathrm{ml})$ for $2 \mathrm{~h}$ at $37^{\circ} \mathrm{C}$. Digests were analyzed for chondroitin sulfate disaccharides by a high pressure liquid chromatography (HPLC) procedure on a Partisil 5 PAC column [15].

\section{Counting the radioactivity}

The radioactivity of $\left[{ }^{3} \mathrm{H}\right]$ glucosamine and $\left.{ }^{35} \mathrm{~S}\right]$ sulfate was measured with a Beckman scintillation counter. Optiphase 'Hi Safe' 3 (LKB) was used as a scintillator.

\section{Statistical analysis}

Statistical analysis of the results was carried out by student's $t$-test.

\section{Northern blotting}

Retroocular tissue fibroblasts (case 1) and adult skin fibroblasts (case 4) at confluence were cul- 
tured with MEM containing 10\% FBS. The cells were rinsed with phosphate buffer saline (PBS) three times and proteoglycans were extracted with 7-8 $\mathrm{ml}$ buffer containing guanidium-thiocyanate (GTC). The extraction and purification of total RNA was performed as described in the previous study [16]. For Northern blotting, an aliquot of total RNA (5 mg) was loaded on $1.2 \%$ denaturing agarose gel.

Human versican cDNA was generated from clone C7 inserted in pBluescript [17] by PCR amplification (Perkin Elmer Cetus). Insert DNA and cDNA generated by PCR were purified with DEAE cellulose paper. Labeling of CDNA, hybridization and quantitation of the results were performed as described previously [16]. All the solutions used for Northern blotting were treated with diethylpyrocarbonate to minimize RNAase activity.

\section{Immunoprecipitation and fluorography}

Retroocular tissue fibroblasts (case 1) at confluent were labeled with [ $\left.{ }^{35} \mathrm{~S}\right]$ sulfate $(140 \mathrm{mCi} / \mathrm{ml})$, $\left[2-{ }^{3} \mathrm{H}\right]$ glycine $(100 \mathrm{mCi} / \mathrm{ml})$ and $[3,4,5-$ ${ }^{3} \mathrm{H}(\mathrm{N})$ ]leucine $(100 \mathrm{mCi} / \mathrm{ml})$ in MEM medium containing $10 \%$ FBS for $24 \mathrm{~h}$. The culture medium was then diluted 3:1 with $4 \times$ immunoprecipitation buffer described by Gehron Robey et al. [18] except for $0.05 \%$ triton, and $1 \times$ concentration deoxycholate was used. Immunoprecipitation was performed by the method described by Buniol [19] with Protein G conjugated Sepharose (pharmacia) instead of Protein A. The anti-human versican rabbit antiserum was raised against human versican N-terminal peptide LHKVKVGKSPPVRC (a kind gift from Dr. Larry W. Fisher, National Institutes of Dental Research, National Institutes of Health). The sample was diluted in $2 \times$ SDS-sample buffer containing 5\% b-mercaptoethanol (b-ME) and applied to 6\% SDS-polyacrylamide gel [20]. Molecular markers were also run as shown in Fig. 5 (200, 97, 69, 46, 30, 21 and $14 \mathrm{kDa}$ ). After electrophoresis, the gel was applied to fluorography [21], dried and exposed to XO-mat film (Kodak) for 2 weeks.

\section{Results}

Effects of $B t_{2} c A M P$ on glycosaminoglycan synthesis by retroocular tissue fibroblasts from a patient with trauma (case 1)

Retroocular tissue fibroblasts from a patient with trauma (case 1 ) were incubated with various concentrations of $\mathrm{Bt}_{2} \mathrm{cAMP}$ for $48 \mathrm{~h}$. Cells were metabolically labeled with $\left[{ }^{3} \mathrm{H}\right]$ glucosamine and [35S]sulfate for the last $24 \mathrm{~h}$. Hyaluronan synthesis was measured as ${ }^{3} \mathrm{H}$ labeled macromolecules susceptible to hyaluronidase digestion (from Streptomyces hyaluronlyticus) in medium samples. The proteoglycan synthesis was measured as ${ }^{35} \mathrm{~S}$ incorporation into macromolecules excluded from the Sephadex G-50 column in the medium and cell layer sample, respectively. The number of cells was not significantly influenced by $\mathrm{Bt}_{2} \mathrm{cAMP}$. $\mathrm{Bt}_{2} \mathrm{cAMP}$ remarkably increased $\left[{ }^{3} \mathrm{H}\right]$ hyaluronan in the medium. It also increased the amount of [35S]proteoglycan in both medium and cell layer fractions in a dose dependent manner (Fig. 1). A statistically significant increase was observed above $1 \mathrm{mmol} / l$ of $\mathrm{Bt}_{2} \mathrm{cAMP}$. In the presence of $5 \mathrm{mmol} /$ $l \mathrm{Bt}_{2} \mathrm{cAMP}$, hyaluronan synthesis increased to $1914 \%$ and $\left[{ }^{35}\right.$ S]proteoglycan increased to $397 \%$ in the medium and $308 \%$ in the cell layer when the value with $0.1 \%$ BSA alone was taken as $100 \%$. The rate of $\left[{ }^{35} \mathrm{~S}\right]$ proteoglycan degradation was examined as described in Methods. In cells cultured with $0.1 \%$ BSA alone for $24 \mathrm{~h}, 34.94 \pm 1.06 \%(n=2)$ of $\left.{ }^{35} \mathrm{~S}\right]$ proteoglycan remained in the cell layer and $36.29 \pm 3.67 \%(n=2)$ of the radioactivity was released into the medium.

The remaining $\left[{ }^{35} \mathrm{~S}\right]$ proteoglycan was degraded to ${ }^{[35}$ S]sulfate. On the other hand, in cells cultured with $0.1 \%$ BSA plus $5 \mathrm{mmol} / \mathrm{l} \mathrm{Bt}_{2}$ cAMP for $24 \mathrm{~h}$, $25.71 \pm 0.08 \%(n=2)$ of $\left[{ }^{35} \mathrm{~S}\right]$ proteoglycan remained in the cell layer and $50.65 \pm 3.56 \%(n=2)$ of the radioactivity was released into the medium. The apparent discrepancy between these values and those listed in Table 1 is due to the fact that the former was obtained from the pulse-chase experiment and the latter was obtained from continous incubation with the isotope, which increases the radioactive sulfate incorporation into proteoglycan in the cell layer. Although $\mathrm{Bt}_{2}$ cAMP increases the rate of proteoglycan secretion from the cell layer compartment, the rate of proteoglycan degrada- 
tion was not affected. The increase in [ ${ }^{35}$ S]proteoglycan therefore reflects the net increase in proteoglycan synthesis by retroocular tissue fibroblasts.

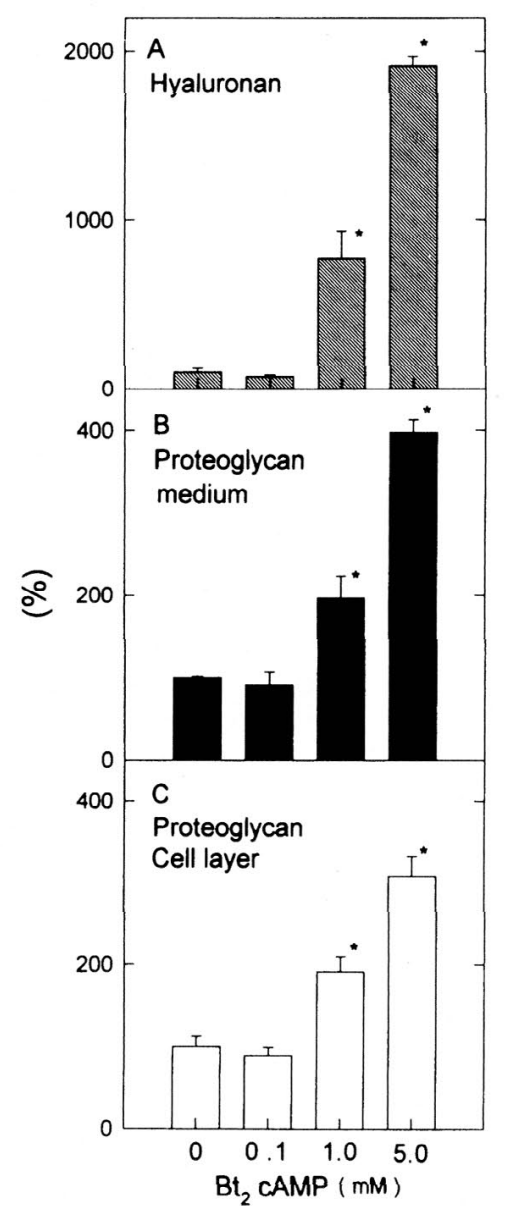

Fig. 1. Effects of $\mathrm{Bt}_{2}$ cAMP on glycosaminoglycan synthesis by retroocular tissue fibroblasts from a patient with trauma (case 1 ). The fibroblasts (case 1) were incubated in the presence of $0.1 \% \mathrm{BSA}$ or $0.1 \% \mathrm{BSA}$ plus various concentration of $\mathrm{Bt}_{2}$ cAMP for $48 \mathrm{~h}$. Hyaluronan synthesis was measured as a radiolabeled macromolecule susceptible to hyaluronidase digestion as described in Method (A). Proteoglycan was measured as ${ }^{35} \mathrm{~S}$ incorporation into macromolecules excluded from the Sephadex G-50 column in the medium (B) and cell layer sample (C), respectively. Results were expressed as a percentage of the value in $0.1 \%$ BSA taken as $100 \%$. Each column and bar represent the mean \pm SD obtained from triplicates. *; $P<0.05$ when compared to the control (culture with $0.1 \% \mathrm{BSA}$ ).
Effects of $\mathrm{Bt}_{2}$ cAMP on characteristics of proteoglycans synthesized by retroocular tissue fibroblasts from a patient with trauma (case 1)

$\left[{ }^{35}\right.$ S]proteoglycan samples were then applied to a Superose 6 column with or without chondroitin sulfate $A B C$ lyase digestion. In cells cultured with $0.1 \%$ BSA, $73 \%$ of medium proteoglycan and $59 \%$ of cell layer proteoglycan were digested by chondroitinase $A B C$ lyase and eluted at $V_{t}$ (Fig. $2 A$ and $2 B$ ). This means that $73 \%$ of medium proteoglycan and $59 \%$ of cell layer proteoglycan have chondroitin sulfate chains as their glycosaminoglycan chains. The same analysis showed that $89 \%$ of medium proteoglycan and $77 \%$ of cell layer proteoglycan have chondroitin sulfate chains as their glycosaminoglycan chains when cultured with 5 mmol/l $\mathrm{Bt}_{2}$ cAMP (Fig. 2C and 2D). Thus, $\mathrm{Bt}_{2}$ cAMP mainly increased chondroitin sulfate proteoglycan synthesis in retroocular tissue fibroblasts in culture.

As was reported in a previous study [5], medium proteoglycans were separated into the large chondroitin sulfate proteoglycan which eluted at $\mathrm{Kd}=0$ and the small chondroitin sulfate proteoglycan which eluted at $\mathrm{Kd}=0.35$ on a Superose 6 column. $\mathrm{Bt}_{2} \mathrm{cAMP}$ increased the large chondroitin sulfate proteoglycan remarkably (Fig. 2C).

Effects of $B t_{2}$ cAMP on glycosaminoglycans synthesized by retroocular tissue fibroblasts and adult skin fibroblasts

Retroocular tissue fibroblasts from patients with trauma (cases 1 and 2), a patient with Graves' ophthalmopathy (case 3) and adult skin fibroblasts (cases 4 and 5) were studied for the effects of 5 $\mathrm{mmol} / \mathrm{l} \mathrm{Bt}_{2}$ cAMP on glycosaminoglycan synthesis. Cells were cultured for $48 \mathrm{~h}$ in the medium containing $0.1 \% \mathrm{BSA}$ or $0.1 \% \mathrm{BSA}$ plus $5 \mathrm{mmol} / \mathrm{l}$ $\mathrm{Bt}_{2}$ cAMP with $\left[{ }^{3} \mathrm{H}\right]$ glucosamine and $\left[{ }^{35} \mathrm{~S}\right]$ sulfate labeling for the last $24 \mathrm{~h}$. The radioactivity of $\left[{ }^{3} \mathrm{H}\right]$ hyaluronan in the medium and that of ${ }^{35}$ S]proteoglycans in the medium and cell layer were counted on the specimen excluded by the Sephadex G-50 column. As shown in Table $1 \mathrm{Bt}_{2}$ cAMP had stimulatory effects on glycosaminoglycan synthesis, especially hyaluronan synthesis by all strains of fibroblasts. The difference from the control was statistically significant in cases 2 and 
Table 1. Effects of $\mathrm{Bt}_{2} \mathrm{cAMP}$ on glycosaminoglycans synthesized by retroocular tissue fibroblasts and adult skin fibroblasts

\begin{tabular}{|c|c|c|c|c|c|}
\hline & \multirow{2}{*}{$\begin{array}{c}\text { Retroocular } \\
\begin{array}{l}\text { Trauma } \\
\text { (case 1) }\end{array}\end{array}$} & \multirow{2}{*}{$\begin{array}{l}\text { Tissue } \\
\begin{array}{l}\text { Trauma } \\
\text { (case 2) }\end{array}\end{array}$} & \multirow{2}{*}{$\begin{array}{c}\text { Fibroblasts } \\
\begin{array}{c}\text { Ophthalmopathy } \\
\text { (case 3) }\end{array}\end{array}$} & \multicolumn{2}{|c|}{ Adult skin fibroblasts } \\
\hline & & & & (case 4) & (case 5) \\
\hline $\begin{array}{r}\text { Number of cells } \\
\left(10^{4} / \text { well }\right)\end{array}$ & 3.11 & 3.72 & 3.41 & 7.69 & 7.55 \\
\hline \multicolumn{6}{|l|}{$\begin{array}{l}\text { Hyaluronan } \\
\qquad\left(\mathrm{pmol} / 10^{4} \text { cells }\right)\end{array}$} \\
\hline $0.1 \%$ BSA (control) & $42 \pm 5.1$ & $169 \pm 16$ & $19 \pm 1.1$ & $198 \pm 15.1$ & $43 \pm 0.1$ \\
\hline $\mathrm{Bt}_{2} \mathrm{cAMP} 5 \mathrm{mmol} / \mathrm{l}$ & $1017 \pm 326^{b}$ & $532 \pm 61^{a}$ & $566 \pm 59 a$ & $3949 \pm 1207 \mathrm{~b}$ & $953 \pm 355^{c}$ \\
\hline \multicolumn{6}{|l|}{$\begin{array}{l}\text { Proteoglycan in medium } \\
\quad\left(\mathrm{cpm} / 10^{4} \text { cells }\right)\end{array}$} \\
\hline $0.1 \%$ BSA (control) & $2331 \pm 656$ & $3855 \pm 376$ & $932 \pm 124$ & $14922 \pm 866$ & $4111 \pm 297$ \\
\hline $\mathrm{Bt}_{2} \mathrm{cAMP} 5 \mathrm{mmol} / \mathrm{l}$ & $8061 \pm 2815^{c}$ & $6048 \pm 539 b$ & $3303 \pm 130^{a}$ & $45032 \pm 6824^{a}$ & $11018 \pm 1711^{b}$ \\
\hline \multicolumn{6}{|l|}{$\begin{array}{l}\text { Proteoglycan in cell layer } \\
\left.\text { (cpm } / 10^{4} \text { cells }\right)\end{array}$} \\
\hline $0.1 \%$ BSA (control) & $889 \pm 347$ & $2450 \pm 559$ & $597 \pm 44$ & $2810 \pm 35$ & $1264 \pm 62$ \\
\hline $\mathrm{Bt}_{2} \mathrm{cAMP} 5 \mathrm{mmol} / \mathrm{l}$ & $2441 \pm 823^{d}$ & $3583 \pm 117 c$ & $3532 \pm 1557 c$ & $5949 \pm 1096^{c}$ & $1908 \pm 678^{c}$ \\
\hline
\end{tabular}

Numbers represent mean \pm SD of two determinants. Cases 1 and 2 were patients with traumatic fracture of the orbit. Case 3 was a patient with Graves' ophthalmopathy who received surgical decompression. Cases 4 and 5 were healthy individuals. Statistical difference between 0.1\% BSA (control) and $\mathrm{Bt}_{2}$ cAMP group was designated as a; $P<0.05, b$; $0.05<P<0.1, \mathrm{c} ; 0.1<P<0.2$, and $\mathrm{d} ; P>0.2$.

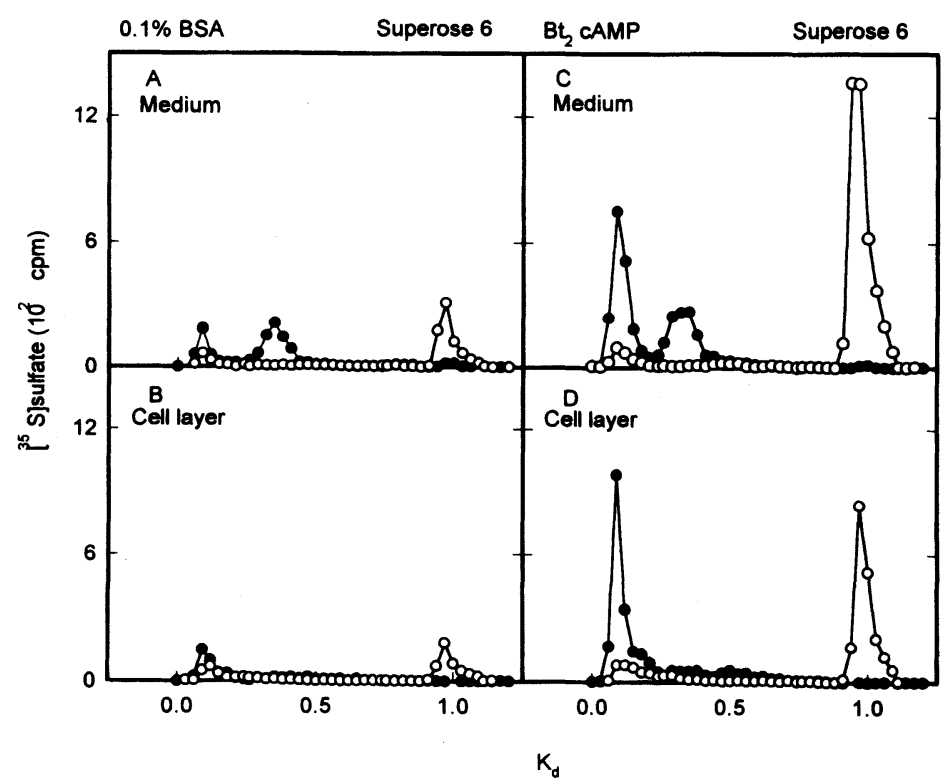

Fig. 2. Effects of $\mathrm{Bt}_{2} \mathrm{cAMP}$ on proteoglycans synthesized by retroocular tissue fibroblasts from a patient with trauma (case 1). Retroocular tissue fibroblasts (case 1 ) were incubated for $48 \mathrm{~h}$ in the absence or presence of $5 \mathrm{mmol} / l \mathrm{Bt}_{2} \mathrm{cAMP}$ with $\left.{ }^{35} \mathrm{~S}\right]$ sulfate labeling for the last $24 \mathrm{~h}$. Proteoglycans were purified from the medium and cell layer samples as described in Methods. The purified proteoglycans were eluted on a Superose 6 column without (solid circles) or with (open circles) chondroitin sulfate ABC lyase treatment. Panels A (medium) and B (cell layer) represent the results obtained in cells cultured with $0.1 \%$ BSA alone. Panels $C$ (medium) and D (cell layer) represent results obtained in cells cultured with $\mathrm{Bt}_{2} \mathrm{cAMP}$. 
3 , but was just short of statistical significance in cases 1, 4 and 5. If the number of observations were increased, the latter may well reach a statistically significant difference. The magnitude of response observed in retroocular tissue fibroblasts was almost the same as that seen in skin fibroblasts.

The effects of $\mathrm{Bt}_{2}$ cAMP on the large proteoglycan and the small proteoglycan were compared between in the case of tissue fibroblasts and adult skin fibroblasts (Fig. 3). In the case of retroocular tissue fibroblasts, $\mathrm{Bt}_{2}$ cAMP increased the large chondroitin sulfate proteoglycan with less effect on the small chondroitin sulfate proteoglycan regardless of the strain, but even in the presence of 5 $\mathrm{mmol} / l \mathrm{Bt}_{2} \mathrm{cAMP}$, adult skin fibroblasts predominantly synthesize the small instead of the large chondroitin sulfate proteoglycan.

\section{Discussion}

$\mathrm{Bt}_{2}$ cAMP stimulated both hyaluronan and pro- teoglycan synthesis by retroocular tissue fibroblasts and adult skin fibroblasts regardless of the strains, but a relatively high concentration of $\mathrm{Bt}_{2} \mathrm{CAMP}$ is required to demonstrate statistically significant difference. Sisson et al. reported that $12.7 \times 10^{-4}$ $\mathrm{mol} / \mathrm{l} \mathrm{Bt}_{2}$ cAMP failed to stimulate glycosaminoglycan synthesis by retroocular tissue fibroblasts [22]. One reason for the difference from the results of our study may be the amount of $\mathrm{Bt}_{2} \mathrm{CAMP}$ used. Another reason may be the method employed. The methods available at that time for extraction of glycosaminoglycan were ethylpiridium precipitation of methanol extract, and for the analyses of glycosaminoglycan, borate carbazole. These methods are now considered to be incomplete for the analyses of glycosaminoglycan.

Hyaluronan synthesis was measured as $\left[{ }^{3} \mathrm{H}\right]$ glucosamine incorporation into macromolecule which is susceptible to hyaluronidase digestion (from Streptomyces hyaluronlyticus). The specific activity of $\left[{ }^{3} \mathrm{H}\right]$ glucosamine is known to change remarkably with culture conditions, because

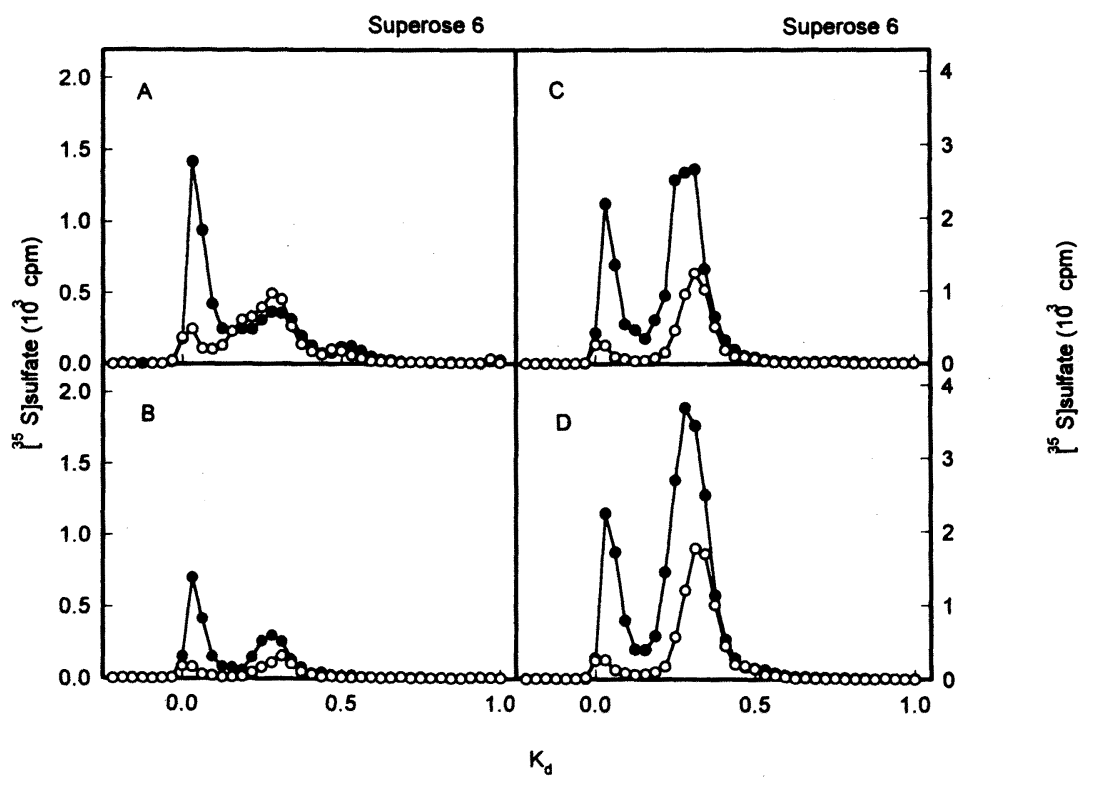

Fig. 3. Effects of $\mathrm{Bt}_{2} \mathrm{cAMP}$ on proteoglycans secreted by retroocular tissue fibroblasts from a patient with trauma (case 2), a patient with Graves' ophthalmopathy (case 3 ) and adult skin fibroblasts (cases 4 and 5). Firbroblasts were incubated for $48 \mathrm{~h}$ in medium containing $0.1 \%$ BSA (open circles) or $0.1 \% \mathrm{BSA}$ plus $5 \mathrm{mmol} / / \mathrm{Bt}_{2} \mathrm{cAMP}$ (solid circles). Proteoglycans purified from the medium sample were analyzed on a Superose 6 column. Panel A (case 2) and Panel B (case 3) represent results obtained from retroocular tissue fibroblasts. Panel $C$ (case 4) and Panel D (case 5) represent results obtained from adult skin fibroblasts. 
$\left[{ }^{3} \mathrm{H}\right]$ glucosamine is diluted several hundred times by intracellular glucosamine whose pool size changes with culture conditions [13]. The specific activity of $\left[{ }^{3} \mathrm{H}\right]$ glucosamine in each culture should be measured for accurate comparison between different culture conditions. This step is crucial in analyzing the effects of $\mathrm{Bt}_{2}$ cAMP [14]. Bt $\mathrm{Bt}_{2}$ cAMP at a concentration of $5 \mathrm{mmol} / \mathrm{l}$ diluted the specific activity of $\left[{ }^{3} \mathrm{H}\right]$ glucosamine to $20-40 \%$ in retroocular tissue fibroblasts and $50-60 \%$ in adult skin fibroblasts (data not shown). $\left[{ }^{3} \mathrm{H}\right]$ hyaluronan compared without adjustment of the specific activity of $\left[{ }^{3} \mathrm{H}\right]$ glucosamine is therefore underestimated by $20-40 \%$ of its real value in retroocular tissue fibroblasts.

In the presence of $5 \mathrm{mmol} / \mathrm{l} \mathrm{Bt}_{2} \mathrm{cAMP}$, the large proteoglycan is the major proteoglycan synthesized by retroocular tissue fibroblasts, while the small proteoglycan is the major one synthesized by adult skin fibroblasts. Production of the large proteoglycan is one of the characteristics of retroocular tissue fibroblasts when compared with adult skin fibroblasts cultured with medium containing 10\% FBS. Platelet derived growth factor (PDGF) also stimulated the large proteoglycan synthesis by retroocular tissue fibroblasts and had little effect on the proteoglycan synthesis by adult skin fibroblasts [5]. These observations emphasize that retroocular tissue fibroblasts have a unique character in regard to glycosaminoglycan synthesis when compared with adult skin fibroblasts. Although there was observed an increase in proteoglycan synthesis by adult skin fibroblasts culture in the present experiments, the results were apparently contradictory to our previous reports [12], in which we reported that $\mathrm{Bt}_{2} \mathrm{CAMP}$ failed to stimulate proteoglycan synthesis. The discrepancy may be due to the origin of the skin fibroblasts: in our previous experiments, fibroblasts were obtained from the lower leg of a 14-year-old Japanese female while in the present experiments fibroblasts were from either the left thigh of a 66-year-old black male (case 5) or some unidentified part of his body (case 4 ).

Analysis of the large proteoglycan by SDS-PAGE suggested that this proteoglycan is compatible with versican [5]. Versican is a proteoglycan first described in human fibroblasts. Its core protein contains a consensus sequence for hyaluronan binding [23]. Versican is therefore considered to play a role in the organization of the extracellular matrix in combination with hyaluronan, comprising a large molecular complex. Northern blotting and immunoprecipitation confirmed the identity of the large proteoglycan as versican. Northern blotting demonstrated that retroocular tissue fibroblasts cultured in the presence of $10 \%$ FBS express versican mRNA, while adult skin fibroblasts express the mRNA at a much lower level. Phosphoimager showed that the expression of versican mRNA in retroocular tissue fibroblasts is $218 \%$ of that in adult skin firbroblasts when cultured with 10\% FBS (Fig. 4). Retroocular tissue fibroblasts were also labeled with $\left[{ }^{3} \mathrm{H}\right]$ glycine and $\left[{ }^{3} \mathrm{H}\right]$ leucine in the presence of $10 \%$ FBS and the culture medium was immunoprecipitated with anti human versican antibody. There was no specific band before chondroitin sulfate $A B C$ lyase digestion, which agrees with the characteristics of versican which will not enter a gel when it has multiple glycosaminoglycan chains

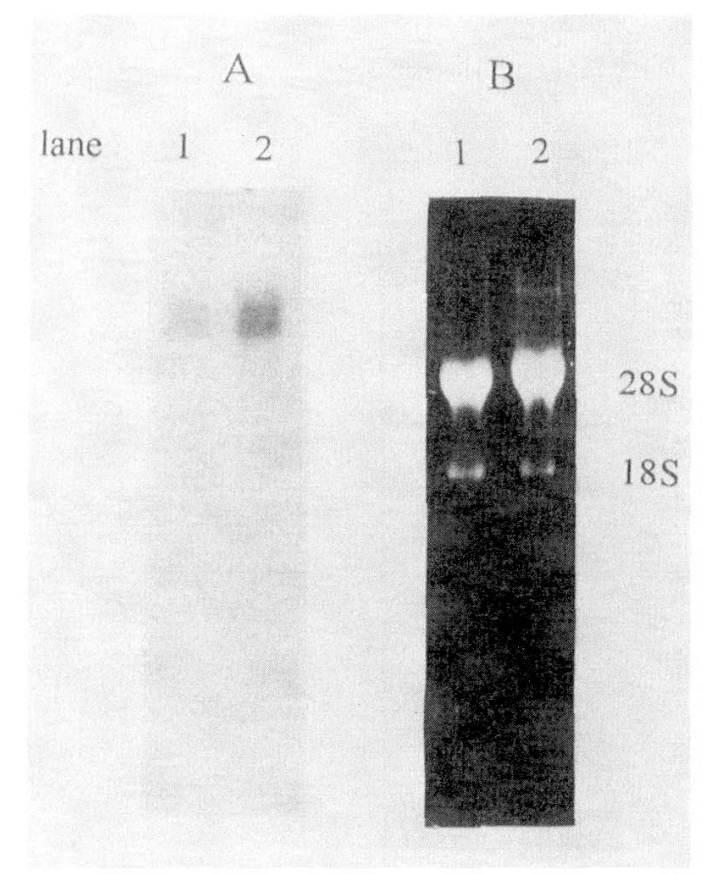

Fig. 4. Northern blotting of mRNA from retroocular tissue fibroblasts (case 1) and adult skin fibroblasts (case 4 ) in cell culture. Total RNA was extracted from retroocular tissue fibroblasts (case 1) and adult skin fibroblasts (case 4) cultured in the presence of $10 \%$ FBS. The Northern blots were probed with cDNA encoding versican (Panel $A$ ). Lane 1 is mRNA from adult skin fibroblasts, lane 2 that from retroocular tissue fibroblasts. Panel B shows a staining pattern of ethidiumbromide which confirms that an equal amount of mRNA was transferred to a nitrocellulose filter. 


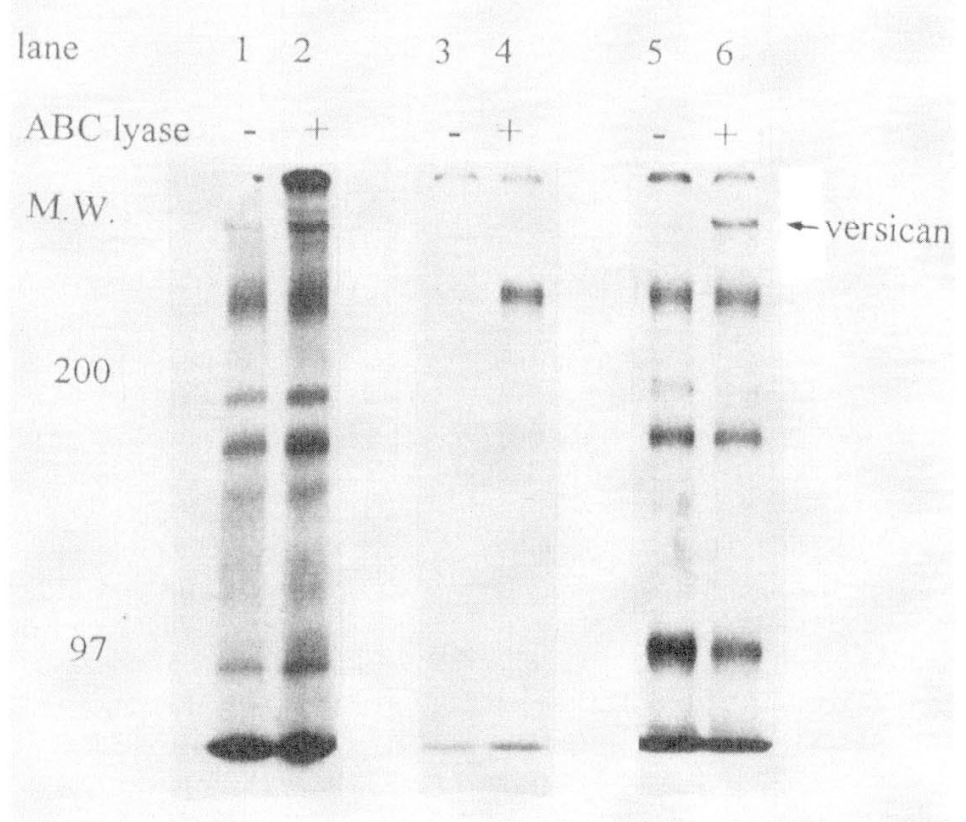

Fig. 5. Immunoprecipitation and SDS-PAGE of retroocular tissue fibroblasts (case 1) culture medium. Retroocular tissue fibroblasts (case 1) at confluency were labeled with $\left[{ }^{35} \mathrm{~S}\right]$ sulfate, $\left[2-{ }^{3} \mathrm{H}\right]$ glycine and $\left[3,4,5-{ }^{3} \mathrm{H}(\mathrm{N})\right]$ leucine in MEM medium containing $10 \%$ FBS for $24 \mathrm{~h}$. Half of the culture medium was digested with chondroitin sulfate $A B C$ lyase after incubation to remove glycosaminoglycan chains and to examine the nature of core-glycoprotein. The medium without (Lanes 1,3,5) and that with chondroitin sulfate $A B C$ lyase (Lanes $2,4,6$ ) were immunoprecipitated by anti-human versican rabbit antiserum bound to Protein G conjugated Sepharose and electrophoresed as described in Methods. Lanes 1 and 2 are medium before immunoprecipitation. Lanes 3 and 4 are protein precipitated by normal rabbit serum. Lanes 5 and 6 are protein precipitated by anti-human versican rabbit anti serum. The band which was positive for staining represents versican.

attached to a core protein (Fig. 5, Lane 5). The specific band was, however, precipitated with an anti versican antibody with a molecular weight higher than $200 \mathrm{kDa}$ after the removal of glycosaminoglycan chains by chondroitin sulfate $A B C$ lyase digestion (Fig. 5, Lane 6).

Recently, Heufelder et al. demonstrated that HSP 72 induction by IgGs from patients with Graves' ophthalmopathy is inhibited by a synthetic peptide from the TSH alpha-subunit (alpha 26-46), suggesting the involvement of TSH receptor in the disease [10]. We have not been able to demonstrate stimulatory effects of IgGs from patients with Graves' ophthalmopathy on retroocular tissue fibroblasts (unpublished observation). The negative results may be due to the experimental design employed. In the present study, we tried to determine whether CAMP, a second messenger of TSH receptor, plays a role in glycosaminoglycan synthesis by retroocular tissue fibroblasts. Our results suggest that the increase in intracellular cAMP will increase glycosaminoglycan production by retroocular tissue fibroblasts, but many factors and cytokines are also capable of stimulating glycosaminoglycan synthesis in retroocular tissue fibroblasts $[5,24]$. Further study should attempt to determine whether cAMP actually play a major role in the pathogenesis of Graves' ophthalmopathy or not.

\section{Acknowledgements}

This study was supported in part by a Grant for the Research on receptor abnormality, from the Ministry of Health and Welfare, and by a Grant from the Ministry of Education, Science and Culture, Japan. 


\section{References}

1. Bahn RS, Smith TJ, Gordon CA (1989) The central role of the fibroblasts in the pathogenesis of extrathyroidal manifestation of Graves' disease. Acta Endocrinol 121 (Suppl 2): 75-81.

2. Hufnagel TJ, Hickey WF, Cobbs WH, Jakobiec A, Iwamoto T, Eagle RC (1984) Immunohistochemical and ultrastructural studies on the exenterated orbital tissue of a patient with Graves' disease. Ophthalmology 91: 1411-1419.

3. Bahn RS, Gorman CA, Johnson CM, Smith TJ (1989) Presence of antibodies in the patients with Graves' disease recognizing a 23 kilodalton fibroblasts protein. J Clin Endocrinol Metab 69: 622-628.

4. Smith TJ, Bahn RS, Gorman CA (1989) Hormonal regulation of hyaluronate synthesis in cultured human fibroblasts: evidence for differences between retroocular and dermal fibroblasts. J Clin Endocrinol Metab 69: 1019-1023.

5. Imai $Y$, Odajima R, Inoue $Y$, Shishiba $Y$ (1992) Effect of growth factors on hyaluronan and proteoglycan synthesis by retroocular tissue fibroblasts of Graves' ophthalmopathy in culture. Acta Endocrinol 126: 541-552.

6. Heufelder AE, Smith TJ, Gorman CA, Barn RS (1991) Increased induction of HLA-DR by interferon-g in cultured fibroblasts derived from patients with Graves' ophthalmopathy and pretibial dermopathy. J Clin Endocrinol Metab 73: 307-313.

7. McKenzie JM, Zakarija M (1977) LATS in Graves' disease. Recent Prog Horm Res 33: 29-57.

8. McKenzie JM, Zakarija M, Sata A (1978) Humoral immunity in Graves' disease. Clin Endocrinol Metab 7: 31-45.

9. Weightman D, Perros P, Sherif I, Janat F, KendallTaylor P (1991) Autoantibodies to eye muscle and orbital fibroblasts in the pathogenesis of thyroidassociated ophthalmopathy. Exp Clin Endocrinol 97: 197-201.

10. Heufelder AE, Bahn RS (1992) Evidence for the presence of a functioning TSH-receptor in retroocular fibroblasts from patients with Graves' ophthalmopathy. Exp Clin Endocrinol 100: 62-67.

11. Rotella CM, Zonefrati R, Toccafondi R, Valente WA, Kohn LD (1986) Ability of monoclonal antibodies to the thyrotropin receptor to increase collagen synthesis in human fibroblasts: An assay which appears to measure exophthalmogenic immunoglobulins in Graves' sera. J Clin Endocrinol Metab 62: 357-367.

12. Shishiba $Y$, Imai $Y$, Odajima R, Ozawa $Y$, Shimizu
$T$ (1992) Immunoglobulin $G$ of patients with circumscribed pretibial myxedema of Graves' disease stimulates proteoglycan synthesis in human skin fibroblasts in culture. Acta Endocrinol 127: 44-51.

13. Yanagishita M, Salustri A, Hascall VC (1989) Specific activity of radiolabeled hexosamines in metabolic labeling experiment. Methods Enzymol 179: 435-445.

14. Salustri A, Ulisse, S, Yanagishita M, Hascall VC (1990) Hyaluronic acid synthesis by mural granulosa cells and cumulus cells in vitro is selectively stimulated by a factor produced by oocytes and by transforming growth factor-b. J Biol Chem 265: 19517-19523.

15. Zebrower ME, Kieras FJ, Brown WT (1986) Analysis by high-performance liquid chromatography of hyaluronic acid and chondroitin sulfate. Anal Biochem 157: 93-99.

16. Ibaraki $\mathrm{K}$, Termine JD, Whitoson $\mathrm{W}$, Young MF (1992) Bone matrix mRNA expression in differentiating fetal bovine osteoblasts. J Bone Miner Res 7: 743-754.

17. LeBaron RG, Zimmerman DR, Ruoslahti E (1992) Hyaluronan binding property of versican. J Biol Chem 267: 10003-10010.

18. Gehron Robey P, Termine JD (1985) Human bone cells in vitro. Calcif Tissue Int 37: 453-460.

19. Buniol IF, Reisfeld RA (1982) Unique glycoproteinproteoglycan complex defined by monoclonal antibody on human myeloma cells. Proc Natl Acad Sci 79: 1245-1249.

20. Laemmli UK (1970) Cleavage of structural proteins during the assembly of the head bacteriophage T4. Nature 227: 680-685.

21. Bonner WM, Laskey RA (1974) A film detection method for tritium-labeled proteins and nucleic acids in polyacrylamide gels. Eur J Biochem 46: 83-88.

22. Sission JC, Vanderburg JA (1972) Lymphocyteretrobulbar fibroblast interaction: mechanism by which stimulation occurs and inhibition of stimulation. Invest Ophthalmol 11: 15-20.

23. Zimmermann DR and Ruoslahti E (1989) Multiple domains of the large fibroblast proteoglycan, versican. The EMBO Journal 8: 2975-2981.

24. Imai $Y$, Odajima $R$, Inoue $Y$, Shishiba $Y$. Effects of interleukin-1-b and transforming growth factor-b on hyaluronan and proteoglycan synthesis by retroocular tissue fibroblasts in cell culture (submitted). 